\title{
Autophagy and apoptotic machinery caused by Polygonum cuspidatum extract in cisplatin-resistant human oral cancer CAR cells
}

\author{
YIN-LAI WANG $^{1 *}$, CHI-TING HORNG $^{2 *}$, MIN-TSANG HSIEH ${ }^{3,4}$, HUNG-CHE CHEN $^{5}$, \\ YU-SYUAN HUANG ${ }^{5}$, JAI-SING YANG ${ }^{6}$, GUO-KAI WANG ${ }^{7}$, JO-HUA CHIANG ${ }^{8}$, \\ HUL-HAN CHEN $^{9}$, CHI-CHENG LU ${ }^{10}$ and FU-AN CHEN ${ }^{5}$
}

\begin{abstract}
Departments of ${ }^{1}$ Dentistry and ${ }^{2}$ Ophthalmology, Kaohsiung Armed Forces General Hospital, Kaohsiung 80284;
${ }^{3}$ School of Pharmacy, China Medical University, Taichung 40402; ${ }^{4}$ Chinese Medicinal Research and Development Center, China Medical University Hospital, Taichung 40447; ${ }^{5}$ Department of Pharmacy and Master Program, Tajen University, Pingtung 90741; ${ }^{6}$ Department of Medical Research, China Medical University Hospital, China Medical University, Taichung 40447, Taiwan, R.O.C.; ${ }^{7}$ School of Pharmacy, Anhui University of Chinese Medicine,

Anhui Key Lab of Modern Chinese Materia Medica, Hefei, Anhui 230012, P.R. China;

${ }^{8}$ Department of Nursing, Chung Jen Catholic Junior College, Chiayi 62241, Taiwan, R.O.C.;

${ }^{9}$ Division of Practice Advancement and Clinical Education, UNC Eshelman School of Pharmacy, University of North Carolina at Chapel Hill, Chapel Hill, NC 275297, USA;

${ }^{10}$ Department of Sport Performance, National Taiwan University of Sport,
\end{abstract} Taichung 40404, Taiwan, R.O.C.

Received September 28, 2018; Accepted January 4, 2019

DOI: $10.3892 /$ or.2019.6985

\begin{abstract}
Polygonum cuspidatum (Hu Zhang) is a traditional Chinese medicine (TCM) and has been revealed to exert anticancer, anti-angiogenesis, anti-human immunodeficiency virus (HIV), anti-hepatitis B virus, anti-microbial, anti-inflammatory, and neuro-protective bio-activities. However, the effect of $P$. cuspidatum extract (PCE) on drug-resistant human oral cancer cells regarding cell death is not fully understood yet. The present study was undertaken to explore the induction of autophagic and apoptotic cell death and to investigate their underlying molecular mechanisms in PCE-treated cisplatin-resistant human oral cancer CAR cells. Our results revealed that PCE was determined via HPLC analytic method,
\end{abstract}

Correspondence to: Dr Chi-Cheng Lu, Department of Sport Performance, National Taiwan University of Sport, No. 16, Section 1, Shuang-Shih Road, Taichung 40404, Taiwan, R.O.C.

E-mail: a722353@gmail.com

Dr Fu-An Chen, Department of Pharmacy and Master Program, Tajen University, 20 Weixin Road, Yanpu, Pingtung 90741, Taiwan, R.O.C.

E-mail: fachen.tajen@yahoo.com.tw

*Contributed equally

Key words: Polygonum cuspidatum extract, autophagy, apoptosis, cisplatin-resistant oral cancer CAR cells and it was revealed that resveratrol may be a major compound in PCE. The data also demonstrated that PCE reduced CAR cell viability in a concentration- and time-dependent response via an MTT assay. PCE had an extremely low toxicity in human normal gingival fibroblasts (HGF). Autophagic and apoptotic cell death was found after PCE treatment by morphological determination. PCE was revealed to induce autophagy as determined using acridine orange (AO), LC3-GFP, monodansylcadaverine (MDC) and LysoTracker Red staining in CAR cells. In addition, PCE was revealed to induce apoptosis in CAR cells via 4',6-diamidino-2-phenylindole (DAPI)/terminal deoxynucleotidyl transferase dUTP nick-end labeling (TUNEL) double staining. PCE significantly stimulated caspase- 9 and -3 activities as revealed using caspase activity assays. PCE markedly increased the protein levels of Atg5, Atg7, Atg12, Beclin-1, LC3, Bax and cleaved caspase-3, while it decreased the protein expression of Bcl-2 in CAR cells as determined by western blotting. In conclusion, our findings are the first to suggest that PCE may be potentially efficacious for the treatment of cisplatin-resistant human oral cancer.

\section{Introduction}

Apoptosis and autophagy are the major processes of the programmed cell death (PCD) and play important roles in cellular homeostasis and diseases $(1,2)$. Induction of autophagic or apoptotic death in tumor cells is one of the best strategies in chemotherapy $(3,4)$. Autophagy is a well-known double-edged sword, promoting survival and/or inducing cell death $(5,6)$. Autophagy-mediated programmed cell death (autophagic 
PCD) is elicited when the cells undergo stress such as cellular damage, nutrient starvation, aging, and pathogen infection (5). Autophagy is characterized by an increase in autophagosomes or autophagic vesicles (double-membrane vesicles), which is mediated by phosphatidylinositol 3-kinase (PI3K) class III, Beclin-1 and autophagy-related protein 14 (Atg14) signals. In addition, autophagosome membrane engagement is complied with the Atg16L1, Atg12, Atg7, Atg5, and LC3 ubiquitin-like conjugation systems. Finally, the autophagosome fuses with the lysosome thus forming an autophagolysosome and degradation of the captured proteins or organelles is carried out by lysosomal enzymes (7). In contrast, apoptosis is characterized by DNA condensation and fragmentation, and the blebbing of nuclear and apoptotic bodies $(8,9)$. The regulators of apoptotic death are Bcl-2 family molecules and caspase cascade $(8,10)$. Pro-apoptotic Bcl-2 family proteins (such as Bax, Bak, Bim and Bid) and anti-apoptotic proteins (such as Bcl-2, Bcl-xL and Mcl-1) can regulate the process of the apoptotic pathway by the ratio of pro-apoptotic Bcl-2 family proteins/anti-apoptotic proteins $(10,11)$.

Polygonum cuspidatum Sieb. et Zucc. (Hu Zhang) is a herbaceous perennial plant found in Taiwan, China, Japan, and America and belongs to the family Polygonaceae $(12,13)$. $P$. cuspidatum has been detected to have various phytochemicals, including essential oils, quinones, stilbenes, flavonoids, coumarins and lignans (12-14). P. cuspidatum has been used to remove jaundice and clear heat-toxin, to promote blood circulation, dispel stasis, expel wind and dampness, to dissipate phlegm, and to suppress coughing in traditional Chinese medicine (TCM) treatments (12). Its clinical applications also include anti-hepatitis, amenorrhea and leucorrhea therapy, arthralgia therapy, and snake bite therapy (12-14). In vitro and in vivo pharmacological studies have demonstrated that the extract from P. cuspidatum has anti-angiogenesis (15), anti-viral $(13,16)$, anti-microbial $(17,18)$, anti-inflammatory $(19-21)$, and neuro-protective properties $(12,22)$. $P$. cuspidatum extract has exhibited antiproliferative effects against various human cancer cells of HL-60, A549, H1650, L-02, HepG2, SHZ-888 and MCF-7/ADM cells (23-28). The methanol and ethyl acetate extracts of $P$. cuspidatum have been revealed to trigger oral cancer KB cell apoptosis through caspase- 3 activation and the regulation of specificity protein 1 (23). Although the various anticancer effects of $P$. cuspidatum have been investigated, its underlying mechanism of autophagy and apoptosis on drug-resistant human oral cancer cells is still unclear. The present study aimed to determine the mechanisms of autophagy and apoptosis induced by the ethanol extract of $P$. cuspidatum (PCE) in cisplatin-resistant human oral cancer CAR cells.

\section{Materials and methods}

Plant extraction procedures and analytic method. Dried Polygonum cuspidatum Sieb. et Zucc. (Fig. 1A) was obtained from a traditional Chinese medicine drugstore in Taichung, Taiwan. The sample was powdered to a homogeneous size through a 60 -mesh filter in a mill and then sieved. The powder $(100 \mathrm{~g})$ was extracted twice by $75 \%$ ethanol for $60 \mathrm{~min}$ under reflux at room temperature. The ethanol extract of P. cuspidatum (PCE) was obtained by combining the filtrates dried in a vacuum at $45^{\circ} \mathrm{C}$, and then collecting $40.32 \mathrm{~g}$ of brownish viscous residue, as previously described (29). The analysis was carried out via high-performance liquid chromatography (HPLC) analysis, as previously described $(30,31)$, using a Shimadzu LC-20A system consisting of a CBM-20A HPLC pump, a FRC-10A autosampler, UV and PDA detectors, and Merck Purospher STAR RP-18 end-capped 250-4.6 mm $(5 \mu \mathrm{m})$ column. Chromatograms were monitored at $280 \mathrm{~nm}$ using a UV detector. $\mathrm{H}_{2} \mathrm{O}$ (containing $0.2 \%$ formic acid) was used as solvent $\mathrm{A}$ and acetonitrile was used as solvent $\mathrm{B}$. Following the injection of $10 \mu \mathrm{l}$ of the sample, the flow rate of the mobile phases was maintained at $1 \mathrm{ml} / \mathrm{min}$. A linear HPLC gradient was employed: i) 0.0-10.0 min linear gradient from 10 to $40 \%$ of solvent B; ii) 10.0-32.0 min linear gradient from 40 to $85 \%$ of solvent $\mathrm{B}$; iii) $32.0-40.0 \mathrm{~min}$ isocratic at $85 \%$ of solvent B. Furthermore, the PCE was re-suspended and dissolved in dimethyl sulfoxide (DMSO) and used for further in vitro experiments.

Chemicals and reagents. Dulbecco's modified Eagle's medium (DMEM), DMEM/F12 1:1 medium, fetal bovine serum (FBS), L-glutamine, and penicillin/streptomycin were purchased from HyClone; GE Healthcare Life Sciences (Logan, UT, USA). Cisplatin, DMSO, monodansylcadaverine (MDC), thiazolyl blue tetrazolium bromide (MTT), and resveratrol were obtained from Sigma-Aldrich; Merck KGaA (Darmstadt, Germany). Acridine orange (AO), 4',6-diamidino-2-phenylindole (DAPI), LysoTracker Red DND-99, and trypsin-EDTA were obtained from Thermo Fisher Scientific, Inc. (Waltham, MA, USA). The primary antibodies [anti-Atg5 (cat. no. GTX113309), anti-Atg7 (cat. no. GTX113613), anti-Atg12 (cat. no. GTX629815), anti-Beclin-1 (cat. no. GTX631396), anti-LC3 (cat. no. GTX39752), anti-Bax (cat. no. GTX109683), anti-Bcl-2 (cat. no. GTX100064), anti-caspase-3 (cat. no. GTX110543) (all 1:1,000 dilution) and anti- $\beta$-actin (cat. no. GTX109639) (1:5,000 dilution)] and the anti-rabbit (cat. no. GTX213110-01) or anti-mouse (cat. no. GTX213111-01) IgG-horseradish peroxidase (HRP) secondary antibodies (1:10,000 dilution) were all purchased from GeneTex International Corporation (Hsinchu, Taiwan).

Cell culture. The cisplatin-resistant CAR cells were established as previous methods $(3,32-39)$. The parental human tongue squamous cell carcinoma CAL 27 cell line was obtained from American Type Culture Collection (ATCC; Manassas, VA, USA) after increasing exposure to $10-80 \mu \mathrm{M}$ of cisplatin for 10 cycles and at least stably resistant to $80 \mu \mathrm{M}$ cisplatin. CAR cells were cultured in DMEM with $10 \%$ FBS, $100 \mathrm{U} / \mathrm{ml}$ penicillin, $100 \mu \mathrm{g} / \mathrm{ml}$ streptomycin, $2 \mathrm{mM} \mathrm{L}$-glutamine and $80 \mu \mathrm{M}$ cisplatin. Normal human primary gingival fibroblast (HGF) was purchased from CLS Cell Lines Service GmbH (Eppelheim, Germany) and cultivated in DMEM/F12 1:1 medium with $10 \%$ FBS, $100 \mu \mathrm{g} / \mathrm{ml}$ streptomycin, $100 \mathrm{U} / \mathrm{ml}$ penicillin and $2 \mathrm{mM} \mathrm{L}$-glutamine. All cells were cultured in a $37^{\circ} \mathrm{C}$ humidified incubator with $5 \% \mathrm{CO}_{2}$.

Cell viability assay and morphological changes. CAR or HGF cells ( $1 \times 10^{4}$ cells/well) were plated on 96-well plates and exposed to $50,100,150$ and $200 \mu \mathrm{g} / \mathrm{ml}$ of PCE for 24 and $48 \mathrm{~h}$. At the end of treatment, each medium containing $500 \mu \mathrm{g} / \mathrm{ml}$ MTT 
A

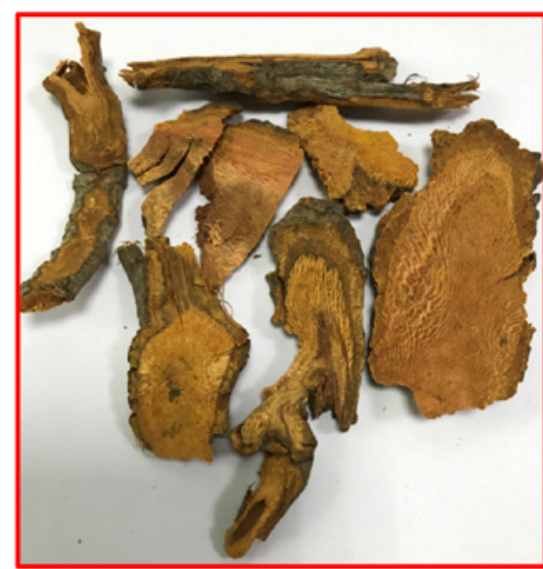

B

Polygonum cuspidatum Sied. et Zucc.
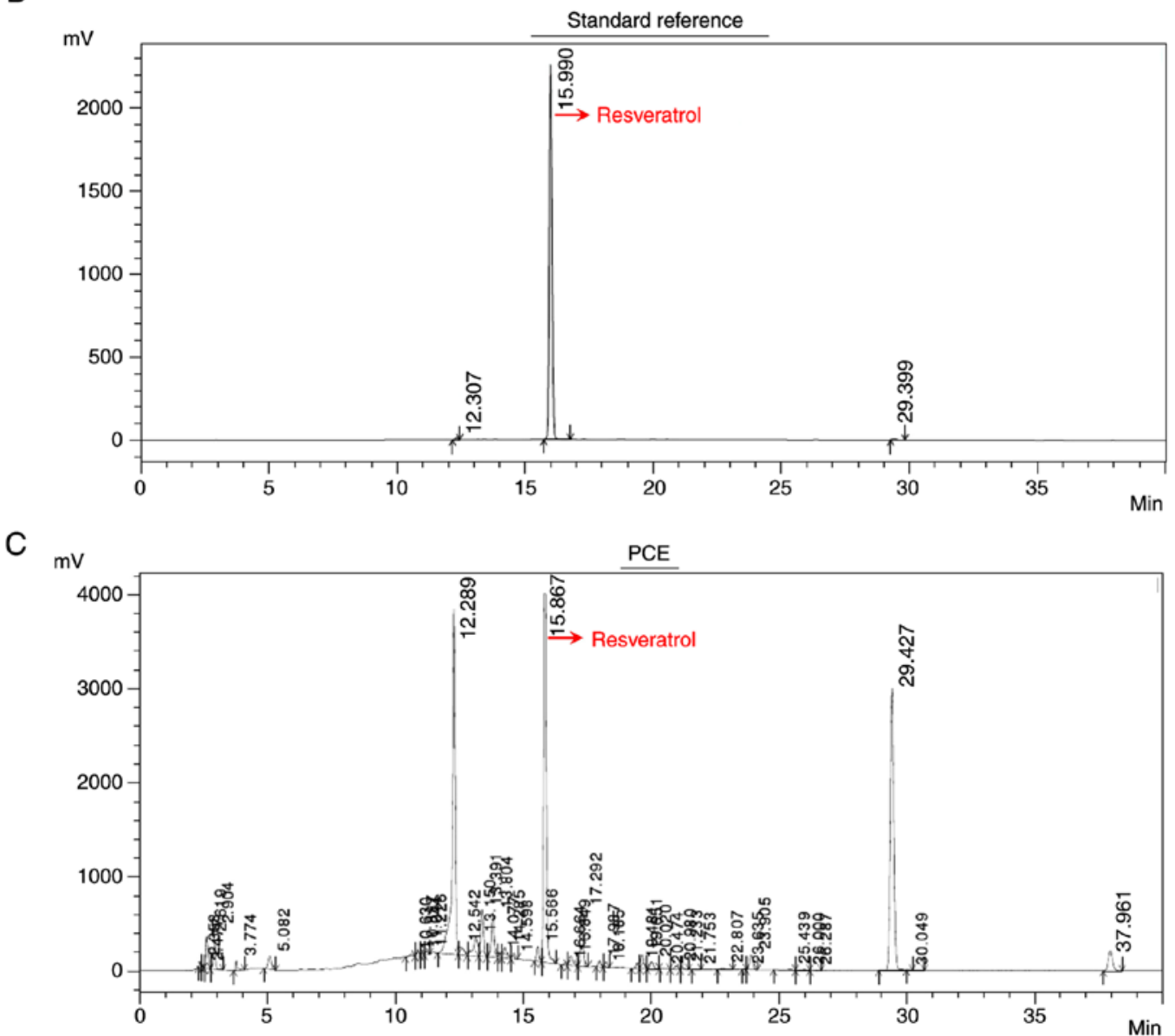

Figure 1. Polygonum cuspidatum and HPLC pattern of resveratrol and PCE. (A) Materia medica of the roots of Polygonum cuspidatum Sieb. et Zucc. (B) Standard reference: Resveratrol (peak at $15.990 \mathrm{~min}$ ). (C) The HPLC chromatogram of ethanol extract of PCE revealed a retention time at 15.867 min. HPLC, high performance liquid chromatography; PCE, P. cuspidatum extract.

solution was added for an additional $3 \mathrm{~h}$ before the medium was discarded from each well. The blue formazan product was dissolved by $100 \mu \mathrm{l}$ DMSO, and the optical density was spectrophotometrically detected at an absorbance of $570 \mathrm{~nm}$, as previously described $(40,41)$. Cell morphological changes (autophagic vacuoles and apoptotic characteristics) were visualized and photographed via a phase-contrast microscope, as previously described $(40,42)$.

Autophagy assays. CAR cells $\left(5 \times 10^{4}\right.$ cells $\left./ \mathrm{ml}\right)$ were plated on sterile coverslips in tissue culture plates and then treated with
$150 \mu \mathrm{g} / \mathrm{ml}$ PCE for $24 \mathrm{~h}$. Cells were then individually stained with either $1 \mu \mathrm{g} / \mathrm{ml} \mathrm{AO}, 100 \mu \mathrm{M}$ MDC, and $1 \mu \mathrm{g} / \mathrm{ml}$ LysoTracker Red DND-99 for 15 min, as previously described $(35,36)$. The autophagy marker LC3 was detected via the Premo Autophagy Sensor LC3B-GFP (BacMam 2.0) Kit (Thermo Fisher Scientific, Inc.) following the manufacturer's protocol. The fluorescent images were immediately monitored and photographed by fluorescence microscopy (Nikon Corp., Melville, NY, USA).

Apoptosis assay. CAR cells $\left(2 \times 10^{5}\right.$ cells/well $)$ plated on 12 -well plates were incubated with $150 \mu \mathrm{g} / \mathrm{ml}$ PCE. After 

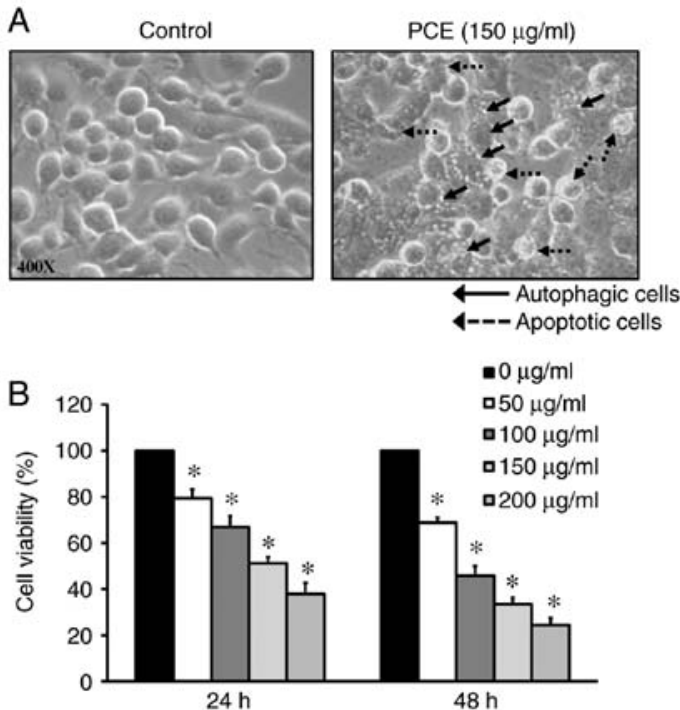
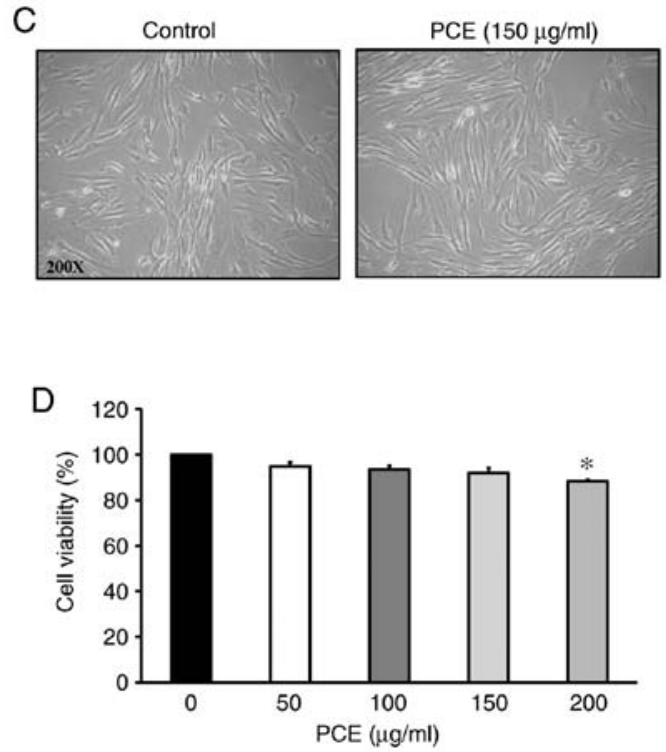

Figure 2. Effect(s) of PCE on CAR and normal HGF cell morphological examination and viability. CAR cells were exposed to the indicated concentrations $(0,50,100,150$ and $200 \mu \mathrm{g} / \mathrm{ml})$ of PCE for 24 or $48 \mathrm{~h}$. (A) The morphological changes of CAR cells were photographed with a phase-contrast microscope at x400 magnifications. (B) CAR cell viability was assessed by an MTT assay. (C) HGF cells were treated with indicated concentrations of PCE for 24 h. The morphological changes of HGF cells were photographed at x200 magnifications. (D) Cell viability of HGF cells was detected. The results are expressed as the mean $\pm \mathrm{SD}(\mathrm{n}=3)$. ${ }^{*} \mathrm{P}<0.05$ vs. untreated control. PCE, P. cuspidatum extract; HGF, human gingival fibroblasts.

exposure for $24 \mathrm{~h}$, TdT-mediated dUTP-X nick-end labeling (TUNEL) positive cells were determined via the In Situ Cell Death Detection kit, Fluorescein (Roche, Sigma-Aldrich; Merck KGaA) according to manufacturer's instructions. The cell image was photographed using a fluorescence microscope after being counterstained with $1 \mu \mathrm{g} / \mathrm{ml}$ DAPI dye, as previously described (3).

Caspase -3 and -9 activity assays. CAR cells $\left(5 \times 10^{6}\right.$ cells $/ 75 \mathrm{~T}$ flask) were treated with or without $150 \mu \mathrm{g} / \mathrm{ml}$ PCE for 12 and $24 \mathrm{~h}$. Cell lysates were collected, and the supernatant was incubated in the supplied reaction buffer with dithiothreitol and the caspase-specific substrates [Asp-Glu-Val-Asp (DEAD) for caspase-3; Leu-Glu-His-Asp (LEHD) for caspase-9] labeled with $p$-nitroaniline (pNA) at $37^{\circ} \mathrm{C}$ for $2 \mathrm{~h}$ in the dark following the manufacturer's protocols (Caspase-3 and Caspase-9 Colorimetric Assay Kits; R\&D Systems, Inc., Minneapolis, MN, USA).

Western blotting. CAR cells $\left(5 \times 10^{6}\right.$ cells/75T flask) were exposed to 0,150 and $200 \mu \mathrm{g} / \mathrm{ml}$ PCE for $24 \mathrm{~h}$. Whole-cell lysates were isolated with Trident RIPA Lysis Buffer (GeneTex International Corp.), and the protein concentration was quantified using Pierce BCA Protein Assay Kit (Thermo Fisher Scientific, Inc.). Equal amounts $(40 \mu \mathrm{g})$ of protein samples were separated using 10-12\% SDS-PAGE, as previously described (42). The separated protein was transferred to an Immobilon-P Transfer Membrane (EMD Millipore, Billerica, MA, USA) via use of electroblotting. The membranes were soaked in 5\% skim milk and individually incubated with the primary antibodies, including Atg5, Atg7, Atg12, Beclin-1,LC3, Bax, Bcl-2, caspase- 3 and $\beta$-actin overnight at $4^{\circ} \mathrm{C}$, as well as the appropriate horseradish peroxidase-conjugated secondary antibodies for $1 \mathrm{~h}$ at room temperature to hybridize targeted protein using an Immobilon Western Chemiluminescent
HRP Substrate (EMD Millipore). All bands were normalized to the level of $\beta$-actin for each lane, and their densitometric quantification was carried out using NIH ImageJ 1.47 software (National Institutes of Health, Bethesda, MD, USA).

Statistical analysis. All data were reported as the mean \pm standard deviation (SD) of triplicate samples. The significant differences of data were subjected to one-way analysis of variance (ANOVA) followed by Dunnett's test using SPSS software version 16.0 (SPSS, Inc., Chicago, IL, USA). A P-value of $<0.05$ was considered to indicate a statistically significant difference.

\section{Results}

Resveratrol is one of the major compounds in PCE. The result from the HPLC analysis revealed that the major peak of the standard reference (resveratrol) appeared at $15.990 \mathrm{~min}$ (Fig. 1B). In addition, the data indicated that PCE had several peaks at various retention time intervals, indicating that PCE possessed multiple components. The retention time of the peak at 15.867 min was identified as resveratrol (Fig. 1C). Therefore, resveratrol may be one of the major compounds in PCE.

PCE inhibits cell viability in cisplatin-resistant human oral cancer CAR cells. PCE promoted the formation of autophagic vacuoles and apoptotic bodies after exposure to $150 \mu \mathrm{g} / \mathrm{ml}$ PCE for $24 \mathrm{~h}$ in CAR cells (Fig. 2A). PCE also reduced viable CAR cells in a time- and concentration-dependent manner (Fig. 2B). These findings indicated that autophagy and apoptotic mechanisms may be present in PCE-treated CAR cells. Notably, no morphological changes (Fig. 2C) and cytotoxic effects (Fig. 2D) were found on normal HGF cells. Thus, PCE exerted lower cytotoxicity in normal oral cells and triggered autophagic and apoptotic mechanisms in CAR cells. 


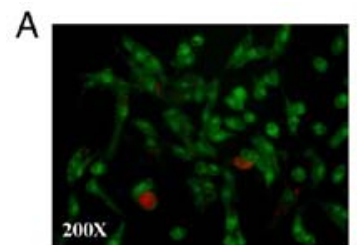

Control

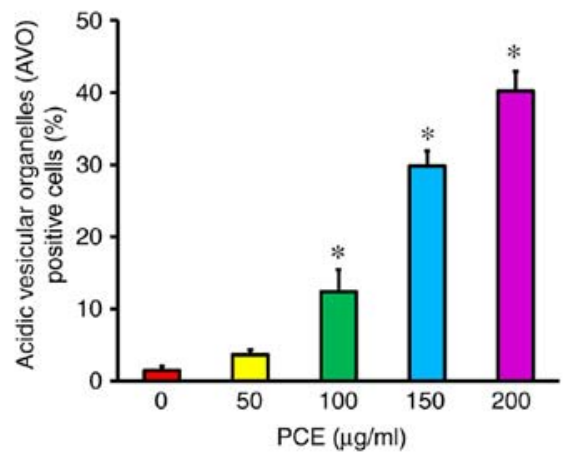

C

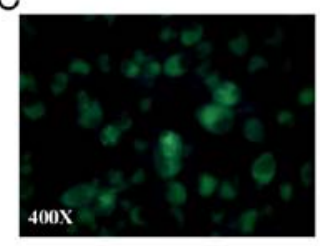

Control

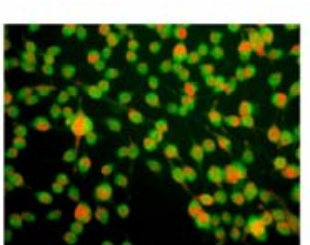

PCE $(150 \mu \mathrm{g} / \mathrm{ml})$

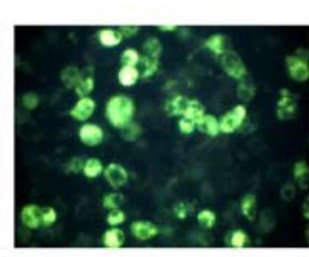

PCE $(150 \mu \mathrm{g} / \mathrm{ml})$

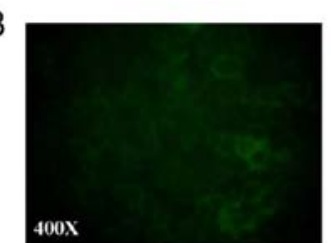

Control

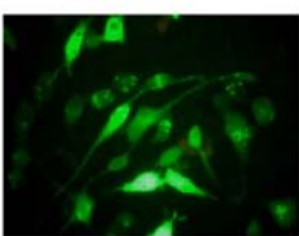

PCE $(150 \mu \mathrm{g} / \mathrm{ml})$

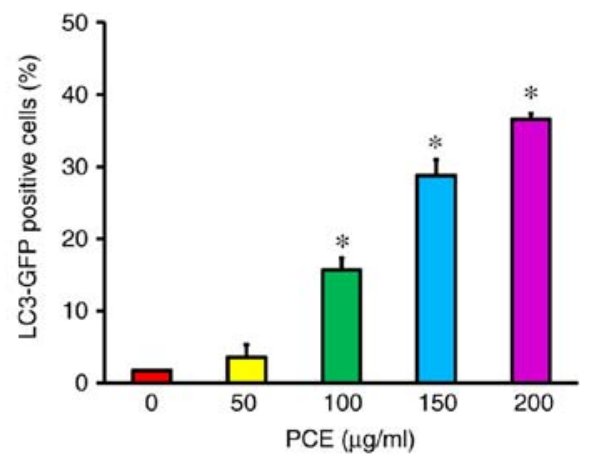

D

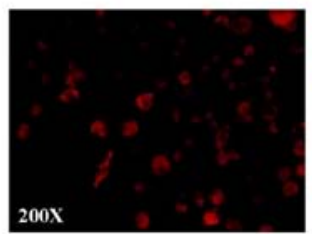

Control

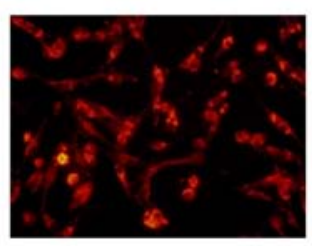

PCE $(150 \mu \mathrm{g} / \mathrm{ml})$

Figure 3. Effect(s) of PCE on autophagy of CAR cells. Cells were exposed to 0, 50, 100, 150 and $200 \mu \mathrm{g} / \mathrm{ml}$ of PCE for $24 \mathrm{~h}$ and then were harvested. (A) AO staining was used to detect AVOs (red fluorescence) (at x200 magnifications), and the data was quantified. (B) An LC3B-GFP kit was applied to monitor LC3B expression (green fluorescence) (at $\mathrm{x} 400$ magnifications), and the data was quantified. The results are expressed as the mean $\pm \mathrm{SD}$ ( $\mathrm{n}=3$ ). ${ }^{*} \mathrm{P}<0.05$ vs. untreated control. Cells were with or without $150 \mu \mathrm{g} / \mathrm{ml}$ PCE exposure for $24 \mathrm{~h}$. Cells were individually stained with (C) MDC dye (green fluorescence) (at x400 magnifications) and (D) LysoTracker Red DND-99 (red fluorescence) (at x200 magnifications) to detect autophagic vacuoles and lysosomal enzyme activity, respectively, as described in the Materials and methods. PCE, P. cuspidatum extract; AO, acridine orange; AVOs, acidic vesicular organelles; MDC, monodansylcadaverine.

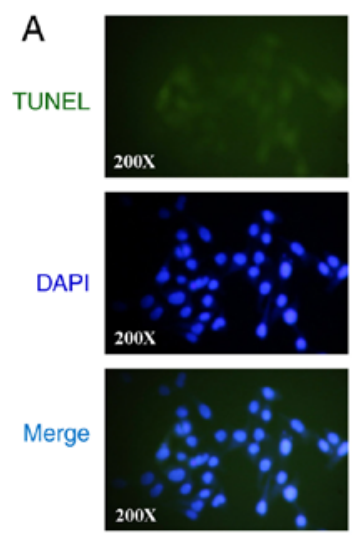

Control
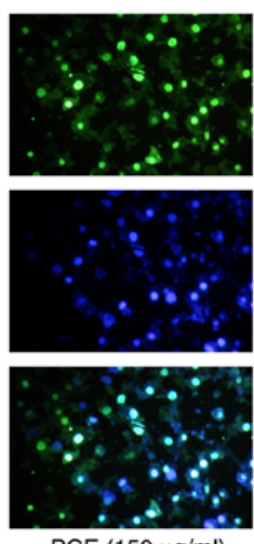

B

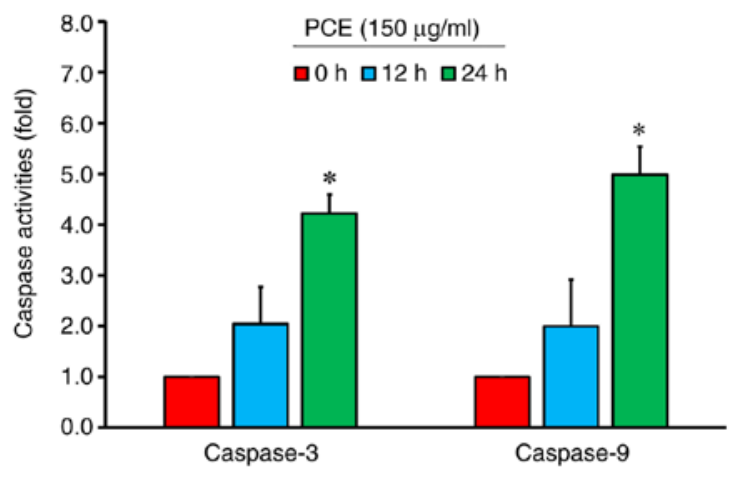

Figure 4. Effect(s) of PCE on apoptotic characteristic(s) of CAR cells. Cells were exposed to $150 \mu \mathrm{g} / \mathrm{ml}$ PCE for 12 or 24 h. (A) Apoptotic DNA breaks and DNA condensation were determined via TUNEL and DAPI staining, at x200 magnifications. (B) The activities of caspase-3 and -9 were estimated, as described in the Materials and methods. The results are expressed as the mean $\pm \mathrm{SD}(\mathrm{n}=3)$. ${ }^{*} \mathrm{P}<0.05$ vs. untreated control. PCE, $P$. cuspidatum extract; DAPI, 4',6-diamidino-2-phenylindole; TUNEL, terminal deoxynucleotidyl transferase dUTP nick-end labeling.

PCE induces autophagy in CAR cells. To determine PCE-induced autophagy, CAR cells were incubated with different concentrations of PCE for $24 \mathrm{~h}$, and then monitored for the formation of acidic vesicular organelles (AVOs) and a punctate pattern of LC3. PCE increased the red fluorescence intensity in the cytoplasm compared to the control cells via AO staining, indicating that PCE led to AVO occurrence (Fig. 3A). PCE also caused the punctate pattern of LC3-GFP in CAR cells (Fig. 3B). In addition, autophagic evidence was also demonstrated in cells probed with MDC and LysoTracker Red, respectively. Our results revealed that autophagic vacuoles and lysosome activity were individually observed 


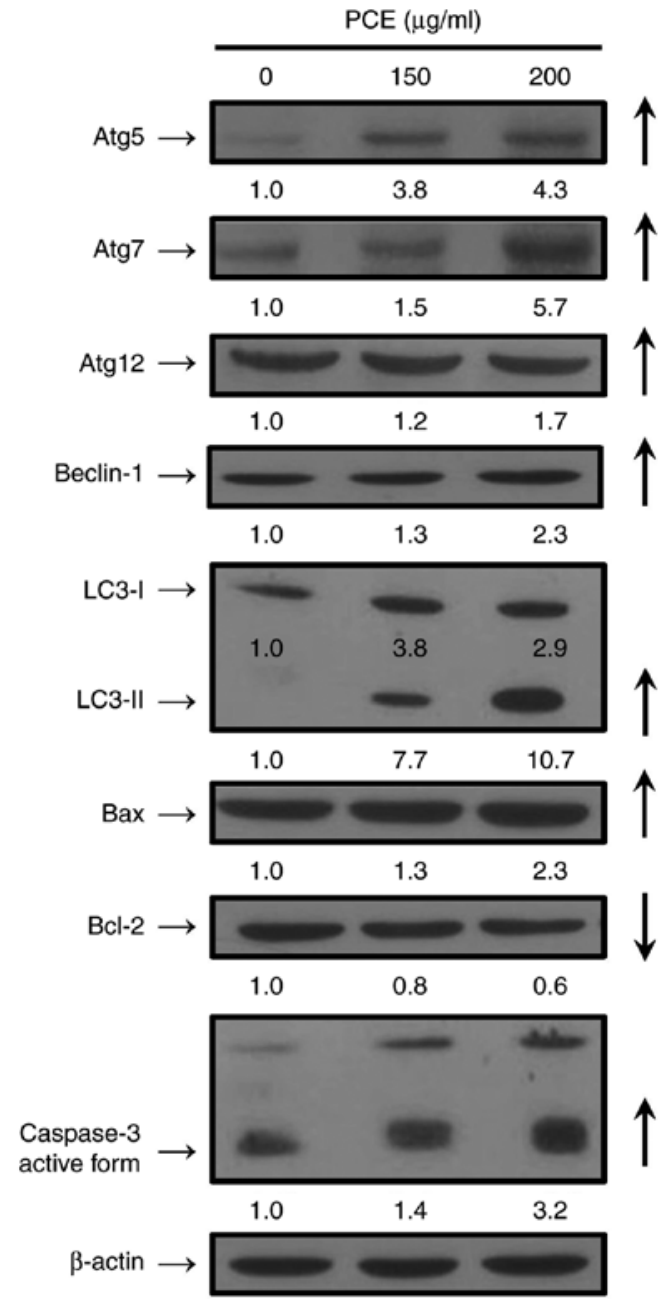

Figure 5. Effect(s) of PCE on autophagy- and apoptosis-regulated protein molecules of CAR cells. The cell lysates from vehicle control or 150 and $200 \mu \mathrm{g} / \mathrm{ml}$ of PCE treatments in CAR cells for $24 \mathrm{~h}$ were determined using immunoblot analysis, as described in the Materials and methods. The protein levels of Atg5, Atg7, Atg12, Beclin-1, LC3, Bax, Bcl-2 and caspase- 3 were detected via western blotting. $\beta$-actin is an internal control. PCE, P. cuspidatum extract.

in PCE-treated CAR cells, and the fluorescence intensity of MDC (green fluorescence) (Fig. 3C) and LysoTracker Red (red fluorescence) (Fig. 3D) staining was directly proportional to CAR cells at $150 \mu \mathrm{g} / \mathrm{ml}$ PCE exposure. Therefore, PCE triggered an autophagic response in CAR cells.

PCE induces the apoptotic process in CAR cells. To assess CAR cell apoptosis induced by PCE, the cells were treated with or without $150 \mu \mathrm{g} / \mathrm{ml}$ PCE for $24 \mathrm{~h}$ and detected by TUNEL/DAPI staining and caspase-3/-9 activity assays. PCE at $150 \mu \mathrm{g} / \mathrm{ml}$ markedly stimulated apoptotic DNA breaks (TUNEL positive) and elicited the occurrence of DNA fragmentation and condensation in CAR cells (Fig. 4A). To further confirm caspase- 3 and caspase- 9 signaling in PCE-treated CAR cells, the activity of caspase- 3 and caspase-9 was detected. Our data revealed that PCE at $150 \mu \mathrm{g} / \mathrm{ml}$ for $24 \mathrm{~h}$ increased the activities of caspase-3 and caspase-9 (Fig. 4B) in CAR cells. The results indicated that PCE-triggered apoptosis resulted from the intrinsic pathway (caspase-3/-9-dependent) in CAR cells.
PCE regulates autophagy- and apoptosis-related protein signaling in CAR cells. PCE at 150 and $200 \mu \mathrm{g} / \mathrm{ml}$ for $24 \mathrm{~h}$ increased the protein levels of Atg5, Atg7, Atg12, Beclin-1, and LC3-II in CAR cells (Fig. 5). Based on the key activation of autophagy markers, it is suggested that PCE induced autophagy in CAR cells. Moreover, after treatment with 150 and $200 \mu \mathrm{g} / \mathrm{ml}$ of PCE, the protein levels of Bax and active form of caspase- 3 were upregulated, while the level of Bcl-2 was downregulated in CAR cells (Fig. 5). Our findings demonstrated that PCE induced apoptotic death via a mitochondria-dependent pathway in CAR cells.

\section{Discussion}

Natural products and traditional Chinese medicine (TCM) have exhibited anticancer activities and low toxicity, and they have been investigated for anticancer activities for some time now $(32,43,44)$. P. cuspidatum (Hu Zhang) is a TCM that has been studied for the treatment of various types of cancers, inflammatory diseases, hepatitis virus infection, HIV, and diarrhea (12-14). It has been demonstrated that physcion, emodin, and resveratrol are the main phytochemicals extracted from the $P$. cuspidatum fraction $(12-14,20,45)$. $P$. cuspidatum is a major and abundant resource of resveratrol since the average content of it is $\sim 1-3 \mathrm{mg} / \mathrm{g}$ (13). Our data (Fig. 1B and C) were also consistent with previous studies $(13,30)$. Resveratrol has a wide spectrum of pharmacological activities such as antioxidant, anti-inflammatory, anti-atherosclerotic, and anticancer effects (46-50). Our previous study reported that resveratrol triggered autophagy and apoptosis in CAR cells (3). Herein, the present study is the first to the best of our knowledge, to report that PCE induced autophagy and apoptosis of CAR cells. The cisplatin-resistant subline CAR cells were originally from a human tongue cancer cell line CAL 27 and established using the method of increasing the concentration of cisplatin (to at least $80 \mu \mathrm{M}$ ) according to a previously described method (3,32-37). Furthermore, the differences from the parental CAL 27 cells and CAR cells were investigated. Our findings revealed that CAR cells were resistant to $80 \mu \mathrm{M}$ cisplatin compared with the parental CAL 27 cells $(3,32,34)$. Notably, multidrug resistance protein 1 (MDR1) revealed a higher expression in CAR cells than in parental CAL 27 cells. Thus far, CAR cells have been a drug-resistant cell platform to test various phytochemicals, traditional Chinese medicine, and novel compounds (3,32-37,39). In the present study, it was firstly demonstrated that PCE reduced cell proliferation in CAR cells (Fig. 2). The half maximal inhibitory concentration $\left(\mathrm{IC}_{50}\right)$ for 24 and $48 \mathrm{~h}$ treatment of PCE in CAR cells were $162.89 \pm 6.28$ and $110.34 \pm 8.21 \mu \mathrm{g} / \mathrm{ml}$, respectively. PCE exhibited low toxicity to normal HGF cells $\left(\mathrm{IC}_{50}>200 \mu \mathrm{g} / \mathrm{ml}\right)$ (Fig. 2). Additionally, our preliminary data indicated that PCE reduced cell viability of the parental CAL 27 cells after 48 -h treatment, and the $\mathrm{IC}_{50}$ value was $188.39 \pm 4.21 \mu \mathrm{g} / \mathrm{ml}$ (data not shown). As a result, PCE induced more selective cytotoxicity in human cisplatin-resistant oral cancer CAR cells while having a low toxicity to normal cells.

Autophagy and apoptosis are the major routes that lead to cell death $(2,5)$. Our study was undertaken to demonstrate that PCE can induce the formation of autophagic 
vesicle and apoptotic bodies (Fig. 2A). It was suggested at the outset that PCE may induce CAR cell death through autophagy and apoptotic pathways. The characteristic of autophagy is to increase autophagosome accumulation in the cytoplasm of cells $(5,6,51)$. The method used for monitoring autophagy in autophagosomes and lysosomal enzyme activity was examining the uptake of fluorescent dyes, such as acridine orange (AO), monodansylcadaverine (MDC), and LysoTracker Red. Furthermore, autophagy-related proteins such as ATGs and LC3 were also detected $(4,49,51)$. In the present study, the results from AO (Fig. 3A), LC3-GFP (Fig. 3B), and MDC staining (Fig. 3C) indicated that PCE induced the formation of autophagic vesicles in a concentration-dependent manner in CAR cells. The LysoTracker Red staining was also used to assess lysosome activity following treatment with PCE (Fig. 3D). PCE also increased the protein level of autophagic proteins, including Atg5, Atg7, Atg12, Beclin-1, and LC3 (Fig. 5) in CAR cells. Notably, 3-methyladenine (3-MA), a specific inhibitor of PI3K kinase class III, inhibited the autophagic vesicle formation induced by PCE (data not shown). Our results support the notion that PCE-induced CAR cell death was mediated through the induction of autophagic death.

In the present study, it was revealed that PCE triggered apoptotic morphological changes in CAR cells (Fig. 2A). PCE induced DNA condensation and fragmentation (Fig. 4A). PCE-induced apoptosis was confirmed by the increase of the activity (Fig. 4B) and protein levels (Fig. 5) of caspase-3 in CAR cells. When the cells undergo apoptotic cell death, the ratio of $\mathrm{Bax} / \mathrm{Bcl}-2$ is enhanced leading to cytochrome $c$ release from the mitochondria (52). Cytochrome $c$ activates the caspase-9/-3 cascade to induce cell apoptosis (10,52). PCE increased the protein level of Bax and decreased the Bcl-2 signal (Fig. 5), indicating that the involvement of the mitochondrial apoptotic pathway contributed to CAR cell death after PCE treatment.

It has been reported that autophagy precedes apoptosis in cervical cancer HeLa cells $(53,54)$ and colorectal DLD1, HT-29 and COLO 201 cells induced by resveratrol (55-57), suggesting that resveratrol triggered apoptotic cell death following the autophagy. Recently, in a separate study, it was demonstrated that resveratrol had an extremely low toxicity in normal HGF cells (3). Resveratrol induced autophagic CAR cell death as observed in AO, LC3-GFP and MDC staining (3). Moreover, resveratrol increased the autophagy-related protein levels (Atg5, Atg7, Atg12, Atg14, Atg16L1, Beclin-1, PI3K class III and LC3), but it decreased rubicon protein expression (3). Resveratrol also induced apoptotic DNA fragmentation, elicited the caspase-3/-9 activities, and increased the protein levels of caspase- 3 and -9 , and Bax, while it decreased the protein level of Bcl-2 $(3,51)$. The present results are in agreement with previous studies $(3,51)$ in reiterating that resveratrol may be a major autophagic inducer in PCE.

In conclusion, our results demonstrated that PCE treatment of CAR cells induced reduction rather than enhancement of autophagic degradation that led to apoptotic cell death. Thus, the present study provided new insight and motivated us to forge ahead regarding the action(s) of PCE and its molecular mechanism(s). PCE could be used for its potential therapeutic use against drug-resistant oral cancer in the near future.

\section{Acknowledgements}

Not applicable.

\section{Funding}

The present study was supported by funds from the Kaohsiung Armed Forces General Hospital (grant no. 105-15).

\section{Availability of data and materials}

The datasets used during the present study are available from the corresponding author upon reasonable request.

\section{Authors' contributions}

YLW, CTH, CCL and FAC conceived and designed the experiments; MTH, HCC, YSH, JSY, GKW and JHC performed the experiments. MTH, JSY, JHC, HHC and CCL analyzed the data; YLW, CTH, CCL and FAC wrote and modified the manuscript. All authors read and approved the manuscript and agree to be accountable for all aspects of the research in ensuring that the accuracy or integrity of any part of the work are appropriately investigated and resolved.

\section{Ethics approval and consent to participate}

Not applicable.

\section{Patient consent for publication}

Not applicable.

\section{Competing interests}

The authors declare that they have no competing interests.

\section{References}

1. Wei Y, Yang P, Cao S and Zhao L: The combination of curcumin and 5-fluorouracil in cancer therapy. Arch Pharm Res 41: 1-13, 2018.

2. Galluzzi L, Vitale I, Aaronson SA, Abrams JM, Adam D, Agostinis P, Alnemri ES, Altucci L, Amelio I, Andrews DW, et al: Molecular mechanisms of cell death: Recommendations of the nomenclature committee on cell death 2018. Cell Death Differ 25: 486-541, 2018.

3. Chang CH, Lee CY, Lu CC, Tsai FJ, Hsu YM, Tsao JW, Juan YN, Chiu HY, Yang JS and Wang CC: Resveratrol-induced autophagy and apoptosis in cisplatin-resistant human oral cancer CAR cells: A key role of AMPK and Akt/mTOR signaling. Int J Oncol 50: 873-882, 2017.

4. Marinkovic M, Šprung M, Buljubašić $M$ and Novak I: Autophagy modulation in cancer: Current knowledge on action and therapy. Oxid Med Cell Longev 2018: 8023821, 2018.

5. Yang JS, Lu CC, Kuo SC, Hsu YM, Tsai SC, Chen SY, Chen YT, Lin YJ, Huang YC, Chen CJ, et al: Autophagy and its link to type II diabetes mellitus. Biomedicine 7: 8, 2017.

6. Zhang SJ, Yang W, Wang C, He WS, Deng HY, Yan YG, Zhang J, Xiang YX and Wang WJ: Autophagy: A double-edged sword in intervertebral disk degeneration. Clin Chim Acta 457: 27-35, 2016.

7. Li YJ, Lei YH, Yao N, Wang CR, Hu N, Ye WC, Zhang DM and Chen ZS: Autophagy and multidrug resistance in cancer. Chin J Cancer 36: 52, 2017.

8. Han Y, Fan S, Qin T, Yang J, Sun Y, Lu Y, Mao J and Li L: Role of autophagy in breast cancer and breast cancer stem cells (Review). Int J Oncol 52: 1057-1070, 2018. 
9. Chowdhury RM, Singh G, Joshi A, Singh DK, Bhatia S and Goswami S: Autophagy and oral cancers: A short review. J Stomatol Oral Maxillofac Surg 119: 37-39, 2018

10. Campbell KJ and Tait SWG: Targeting BCL-2 regulated apoptosis in cancer. Open Biol 8: pii: 180002, 2018.

11. Adams JM and Cory S: The BCL-2 arbiters of apoptosis and their growing role as cancer targets. Cell Death Differ 25: 27-36, 2018.

12. Zhang H, Li C, Kwok ST, Zhang QW and Chan SW: A Review of the pharmacological effects of the dried root of Polygonum cuspidatum (Hu Zhang) and its constituents. Evid Based Complement Alternat Med 2013: 208349, 2013.

13. Peng W, Qin R, Li X and Zhou H: Botany, phytochemistry, pharmacology, and potential application of Polygonum cuspidatum Sieb. et Zucc.: A review. J Ethnopharmacol 148: 729-745, 2013.

14. Nonomura $\mathrm{S}$, Kanagawa $\mathrm{H}$ and Makimoto A: Chemical constituents of polygonaceous plants. I. Studies on the components of Ko-J O-Kon. (Polygonum cuspidatum Sieb. Et Zucc.). Yakugaku Zasshi 83: 988-990, 1963 (In Japanese).

15. Wang S, Zheng Z, Weng Y, Yu Y, Zhang D, Fan W, Dai R and $\mathrm{Hu} \mathrm{Z}$ : Angiogenesis and anti-angiogenesis activity of Chinese medicinal herbal extracts. Life Sci 74: 2467-2478, 2004.

16. Lin CJ, Lin HJ, Chen TH, Hsu YA, Liu CS, Hwang GY and Wan L: Polygonum cuspidatum and its active components inhibit replication of the influenza virus through toll-like receptor 9-induced interferon beta expression. PLoS One 10: e0117602, 2015

17. Jiewei T, Lei W, Xiufeng L, Heming Z, Xiaoguang L, Haiyan F and Yongqiang T: Microbial transformation of resveratrol by endophyte Streptomyces sp. A12 isolated from Polygonum cuspidatum. Nat Prod Res 32: 2343-2346, 2018.

18. Sun W, Qu D, Ma Y, Chen Y, Liu C and Zhou J: Enhanced stability and antibacterial efficacy of a traditional Chinese medicine-mediated silver nanoparticle delivery system. Int J Nanomedicine 9: 5491-5502, 2014.

19. Sohn E, Kim J, Kim CS, Lee YM and Kim JS: Extract of Polygonum cuspidatum attenuates diabetic retinopathy by inhibiting the high-mobility group box-1 (HMGB1) signaling pathway in streptozotocin-induced diabetic rats. Nutrients 8: 140, 2016.

20. Fan P, Zhang T and Hostettmann K: Anti-inflammatory activity of the invasive neophyte Polygonum cuspidatum Sieb. and Zucc. (Polygonaceae) and the chemical comparison of the invasive and native varieties with regard to resveratrol. J Tradit Complement Med 3: 182-187, 2013.

21. Han JH, Koh W, Lee HJ, Lee HJ, Lee EO, Lee SJ, Khil JH, Kim JT, Jeong SJ and Kim SH: Analgesic and anti-inflammatory effects of ethyl acetate fraction of Polygonum cuspidatum in experimental animals. Immunopharmacol Immunotoxicol 34: 191-195, 2012.

22. Shen B, Truong J, Helliwell R, Govindaraghavan S and Sucher NJ: An in vitro study of neuroprotective properties of traditional Chinese herbal medicines thought to promote healthy ageing and longevity. BMC Complement Altern Med 13: 373, 2013.

23. Shin JA, Shim JH, Jeon JG, Choi KH, Choi ES, Cho NP and Cho SD: Apoptotic effect of Polygonum Cuspidatum in oral cancer cells through the regulation of specificity protein 1 . Oral Dis 17: 162-170, 2011.

24. Chang CJ, Ashendel CL, Geahlen RL, McLaughlin JL and Waters DJ: Oncogene signal transduction inhibitors from medicinal plants. In Vivo 10: 185-190, 1996.

25. Owen HC, Appiah S, Hasan N, Ghali L, Elayat G and Bell C: Phytochemical modulation of apoptosis and autophagy: Strategies to overcome chemoresistance in leukemic stem cells in the bone marrow microenvironment. Int Rev Neurobiol 135: 249-278, 2017

26. Jiao Y, Wu Y and Du D: Polydatin inhibits cell proliferation, invasion and migration, and induces cell apoptosis in hepatocellular carcinoma. Braz J Med Biol Res 51: e6867, 2018.

27. Lee KH, Song JL, Park ES, Ju J, Kim HY and Park KY: Anti-obesity effects of starter fermented kimchi on 3T3-L1 adipocytes. Prev Nutr Food Sci 20: 298-302, 2015.

28. Liu J, Zhang Q, Chen K, Liu J, Kuang S, Chen W and Yu Q: Small-molecule STAT3 signaling pathway modulators from Polygonum cuspidatum. Planta Med 78: 1568-1570, 2012.

29. Chang JS, Liu HW, Wang KC, Chen MC, Chiang LC, Hua YC and Lin CC: Ethanol extract of Polygonum cuspidatum inhibits hepatitis B virus in a stable HBV-producing cell line. Antiviral Res 66: 29-34, 2005.

30. Sun P, Qi Y, Mu Z and Wang K: Quantitative determination of resveratrol in Polygonum cuspidatum and its anti-proliferative effect on melanoma A375 cells. Biomed Res 26: 750-754, 2015.
31. Lu CC, Yang SH, Hsia SM, Wu CH and Yen GC: Inhibitory effects of Phyllanthus emblica L. on hepatic steatosis and liver fibrosis in vitro. J Funct Foods 20: 20-30, 2016.

32. Chang HP, Lu CC, Chiang JH, Tsai FJ, Juan YN, Tsao JW, Chiu HY and Yang JS: Pterostilbene modulates the suppression of multidrug resistance protein 1 and triggers autophagic and apoptotic mechanisms in cisplatin-resistant human oral cancer CAR cells via AKT signaling. Int J Oncol: Mar 2, 2018 (Epub ahead of print). doi: 10.3892/ijo.2018.4298.

33. Chiu YJ, Yang JS, Hsu HS, Tsai CH and Ma H: Adipose-derived stem cell conditioned medium attenuates cisplatin-triggered apoptosis in tongue squamous cell carcinoma. Oncol Rep 39: 651-658, 2018.

34. Lee MR, Lin C, Lu CC, Kuo SC, Tsao JW, Juan YN, Chiu HY, Lee FY, Yang JS and Tsai FJ: YC-1 induces $\mathrm{G}_{0} / \mathrm{G}_{1}$ phase arrest and mitochondria-dependent apoptosis in cisplatin-resistant human oral cancer CAR cells. Biomedicine 7: 12, 2017.

35. Yuan CH, Horng CT, Lee CF, Chiang NN, Tsai FJ, Lu CC, Chiang JH, Hsu YM, Yang JS and Chen FA: Epigallocatechin gallate sensitizes cisplatin-resistant oral cancer CAR cell apoptosis and autophagy through stimulating AKT/STAT3 pathway and suppressing multidrug resistance 1 signaling. Environ Toxicol 32: 845-855, 2017.

36. Hsieh MT, Chen HP, Lu CC, Chiang JH, Wu TS, Kuo DH, Huang LJ, Kuo SC and Yang JS: The novel pterostilbene derivative ANK-199 induces autophagic cell death through regulating PI3 kinase class III/beclin 1/Atg-related proteins in cisplatin-resistant CAR human oral cancer cells. Int J Oncol 45: 782-794, 2014

37. Chang PY, Peng SF, Lee CY, Lu CC, Tsai SC, Shieh TM, Wu TS, Tu MG, Chen MY and Yang JS: Curcumin-loaded nanoparticles induce apoptotic cell death through regulation of the function of MDR1 and reactive oxygen species in cisplatin-resistant CAR human oral cancer cells. Int J Oncol 43: 1141-1150, 2013.

38. Gosepath EM, Eckstein N, Hamacher A, Servan K, von Jonquieres G, Lage H, Györffy B, Royer HD and Kassack MU: Acquired cisplatin resistance in the head-neck cancer cell line Cal27 is associated with decreased DKK1 expression and can partially be reversed by overexpression of DKK1. Int J Cancer 123: 2013-2019, 2008.

39. Chen CF, Yang JS, Chen WK, Lu CC, Chiang JH, Chiu HY, Tsai SC, Juan YN, Huang HJ and Way TD: Ursolic acid elicits intrinsic apoptotic machinery by downregulating the phosphorylation of AKT/BAD signaling in human cisplatin-resistant oral cancer CAR cells. Oncol Rep 40: 1752-1760, 2018.

40. Lu CC, Yang JS, Chiang JH, Hour MJ, Lin KL, Lee TH and Chung JG: Cell death caused by quinazolinone HMJ-38 challenge in oral carcinoma CAL 27 cells: Dissections of endoplasmic reticulum stress, mitochondrial dysfunction and tumor xenografts. Biochim Biophys Acta 1840: 2310-2320, 2014.

41. Lu CC, Huang BR, Liao PJ and Yen GC: Ursolic acid triggers nonprogrammed death (necrosis) in human glioblastoma multiforme DBTRG-05MG cells through MPT pore opening and ATP decline. Mol Nutr Food Res 58: 2146-2156, 2014.

42. Chiang JH, Yang JS, Lu CC, Hour MJ, Chang SJ, Lee TH and Chung JG: Newly synthesized quinazolinone HMJ-38 suppresses angiogenetic responses and triggers human umbilical vein endothelial cell apoptosis through p53-modulated Fas/death receptor signaling. Toxicol Appl Pharmacol 269: 150-162, 2013.

43. Chang CH, Wu JB, Yang JS, Lai YJ, Su CH, Lu CC and Hsu YM: The suppressive effects of geniposide and genipin on helicobacter pylori infections in vitro and in vivo. J Food Sci 82: 3021-3028, 2017.

44. Ho TJ, Jiang SJ, Lin GH, Li TS, Yiin LM, Yang JS, Hsieh MC, Wu CC, Lin JG and Chen HP: The in vitro and in vivo wound healing properties of the Chinese herbal medicine 'Jinchuang Ointment'. Evid Based Complement Alternat Med 2016: $1654056,2016$.

45. Wang C, Yang S, Lu H, You H, Ni M, Shan W, Lin T, Gao X, Chen H, Zhou Q, et al: A natural product from Polygonum cuspidatum sieb. Et Zucc. Promotes Tat-dependent HIV latency reversal through triggering P-TEFb's release from 7SK snRNP. PLoS One 10: e142739, 2015.

46. Lange KW and Li S: Resveratrol, pterostilbene, and dementia. Biofactors 44: 83-90, 2018.

47. Rauf A, Imran M, Butt MS, Nadeem M, Peters DG and Mubarak MS: Resveratrol as an anti-cancer agent: A review. Crit Rev Food Sci Nutr 58: 1428-1447, 2018. 
48. Nunes S, Danesi F, Del Rio D and Silva P: Resveratrol and inflammatory bowel disease: The evidence so far. Nutr Res Rev 31: 85-97, 2018.

49. Jardim FR, de Rossi FT, Nascimento MX, da Silva Barros RG, Borges PA, Prescilio IC and de Oliveira MR: Resveratrol and brain mitochondria: A review. Mol Neurobiol 55: 2085-2101, 2018.

50. Perez-Vizcaino F and Fraga CG: Research trends in flavonoids and health. Arch Biochem Biophys 646: 107-112, 2018.

51. Lin W and Xu G: Autophagy: A role in the apoptosis, survival, inflammation, and development of the retina. Ophthalmic Res: 1-8, 2018 (Epub ahead of print).

52. Peña-Blanco A and García-Sáez AJ: Bax, Bak and beyond-mitochondrial performance in apoptosis. FEBS J 285: 416-431, 2018.

53. Garcia-Zepeda SP, Garcia-Villa E, Díaz-Chávez J, HernándezPando R and Gariglio P: Resveratrol induces cell death in cervical cancer cells through apoptosis and autophagy. Eur J Cancer Prev 22: 577-584, 2013.
54. Hsu KF, Wu CL, Huang SC, Wu CM, Hsiao JR, Yo YT, Chen YH, Shiau AL and Chou CY: Cathepsin L mediates resveratrol-induced autophagy and apoptotic cell death in cervical cancer cells. Autophagy 5: 451-460, 2009.

55. Hong EH, Heo EY, Song JH, Kwon BE, Lee JY, Park Y, Kim J, Chang SY, Chin YW, Jeon SM, et al: Trans-scirpusin A showed antitumor effects via autophagy activation and apoptosis induction of colorectal cancer cells. Oncotarget 8: 41401-41411, 2017.

56. Talero E, Ávila-Roman J and Motilva V: Chemoprevention with phytonutrients and microalgae products in chronic inflammation and colon cancer. Curr Pharm Des 18: 3939-3965, 2012.

57. Trincheri NF, Follo C, Nicotra G, Peracchio C, Castino R and Isidoro C: Resveratrol-induced apoptosis depends on the lipid kinase activity of Vps34 and on the formation of autophagolysosomes. Carcinogenesis 29: 381-389, 2008. 